\title{
Inductive Transcutaneous Power Transfer Design for Cardiac Assist Devices by Use of Inhomogeneous Biocompatible Core Material
}

This paper was downloaded from TechRxiv (https://www.techrxiv.org).

\section{LICENSE}

CC BY 4.0

SUBMISSION DATE / POSTED DATE

$12-01-2021 / 16-01-2021$

\section{CITATION}

Fazeli Khalili, Hossein; Kirchner, Jens; Bartunik, Max; Werner, Siegfried; Ebel, Nina; W. Schubert, Dirk; et al. (2021): Inductive Transcutaneous Power Transfer Design for Cardiac Assist Devices by Use of Inhomogeneous Biocompatible Core Material. TechRxiv. Preprint.

https://www.techrxiv.org/articles/preprint/Inductive_Transcutaneous_Power_Transfer_Design_for_Cardiac_Assi: 


\title{
Inductive Transcutaneous Power Transfer Design for Cardiac Assist Devices by Use of Inhomogeneous Biocompatible Core Material
}

\author{
Hossein Fazeli Khalili, Jens Kirchner, Member, IEEE, Max Bartunik, Siegfried Werner, Nina Ebel, \\ Dirk W. Schubert, Michael Weyand, Georg Fischer, Senior Member, IEEE
}

\begin{abstract}
A novel magnetic liquid silicone rubber composite core design applicable to wireless power transfer (WPT) for medical applications is presented. As a case study, the integration of WPT, including the proposed cores for the coils, with ventricular assist devices (VADs) was investigated. This facilitates transferring $4.6 \mathrm{~W}$ of power wirelessly through the skin-layer, which thus allows to dispose of the transcutaneous cable that connects the extracorporal batteries to the implanted blood pump. To enhance the coupling coefficient and consequently increase the WPT efficiency, the geometry of the cores was optimized. This reduces the temperature increase in implant area. The field and thermal simulations were carried out with CST software. The electrical properties of the proposed design as obtained by simulation were validated by measurements. The simulation results perfectly coincide with the measured results. Finally, a new optimized design with additional high permeability core inserts is introduced to further increase the coupling coefficient. The results indicate that the coupling coefficient is increased from 0.31 to 0.52 with the optimized design, in comparison to the case without cores. Moreover, by fixing the initial temperature as $37^{\circ} \mathrm{C}$, the maximum temperature is decreased from $38.19^{\circ} \mathrm{C}$ to $37.27^{\circ} \mathrm{C}$, while keeping the transferred power fixed. Its high magnetic conductivity, biocompatibility, lowloss property, flexibility and Qi-standard compatibility make the proposed WPT design an excellent candidate for the wireless-powering of heart assist devices such as VADs.
\end{abstract}

Index Terms-Wireless power transfer, flexible pot core, implantable material, ventricular assist devices, Qistandard, magnetic liquid silicone rubber composite.

\section{INTRODUCTION}

$\mathbf{T}$ HE number of people suffering from cardiovascular diseases is constantly growing. Moreover, heart failure is among the main causes of human mortality worldwide. To support and treat an ailing heart during heart therapy, ventricular assist devices (VADs) have been developed [1], [2].

H. Fazeli Khalili, J. Kirchner, M. Bartunik and G. Fischer are with the Institute for Electronics Engineering, Friedrich-Alexander-University Erlangen-Nuremberg (FAU), 91058 Erlangen, Germany (e-mail: hossein.fazeli.khalili@fau.de).

S. Werner and D. W. Schubert are with the LSP Institute of Polymer Materials, Friedrich-Alexander-University Erlangen-Nuremberg (FAU), 91058 Erlangen, Germany.

N. Ebel and M. Weyand are with the Department of Cardiac Surgery, University Hospital Erlangen, 91054 Erlangen, Germany.

The first two authors contributed equally to this work.
Initially, these electromechanical pump systems were restricted to a short application period, until either the heart function recovered or a donor was available. Nowadays, owing to major improvements in the new generation of VADs, the treatment time can be extended to five years [3].

However, a weak spot still exists in the design of current VADs. An external power supply and a control unit are required to operate the blood pump of the VAD. A so-called drive line cable passes through the skin to transfer the required power to the blood pump, necessitating a puncture of the dermis, resulting in a wound. Due to the permanent opening in the human skin and the resulting mechanical stress, as the drive line rubs on the contact surfaces, the current powering method can cause infections and therefore a higher mortality rate [4]. To avoid this, and to further extend the treatment time, the driveline can be replaced by an inductive system, which enables wireless power transfer through the skin without requiring an incision.

The design challenges for an implantable wireless power transfer (WPT) module are flexibility and biocompatibility. For technical applications, coils' cores used in WPT modules are typically made of ferrite or other rigid metal based materials. However, conventional rigid cores are not suitable for biological applications such as the scenario at hand, due to the irregular and curved surface of the human body. A slight deviation from a flat contact surface increases the distance between the two cores, which decreases the efficiency of the WPT module. This also leads to a constant localized mechanical pressure on tissue, which may cause damage, or even infection. In contrast, a flexible core material can adapt itself to the complex surface requirements. Silicone rubber material, being in widespread use for breast implants, owing to its outstanding flexibility, is a perfect candidate for use as core material. Moreover, it is usable for medical applications owing to its non-toxicity and antiadhesive properties guaranteeing biocompatibility [5].

However, the main design challenge for the implantable WPT module is its power dissipation, described by its key performance parameter efficiency. Due to power losses such as the electric loss in coils, the electromagnetic energy absorption by surrounding objects and tissues, and the magnetic loss (in the case of using magnetic cores), the local temperature where the WPT module is implanted increases. Since in the 
proposed design, the primary and secondary sides touch the skin surface and the fat-layer, respectively, it is imperative to minimize the temperature increase, to avoid discomfort for patients and possible thermal injury or permanent tissue damage. For this purpose, it is required to use low-loss materials and also improve the power transfer efficiency for the WPT module, since a high-efficiency WPT module design ensures low power dissipation [6]. To realize a highly efficient magnetic flux guidance between the primary and secondary coils, a core material with a high permeability is required. However, silicone has a permeability of one. To increase the permeability of the silicone cores in the fabrication process, magnetic filler powder was added to the liquid silicone rubber material to form a magnetically conductive composite. The permeability of the cores strongly depends on the degree of magnetic filler, the type of filler, the particle shape, size and the size distribution [7], [8]. Recent studies indicate that by using a nanocrystalline filler of deliberately chosen size, the permeability of the resulting composite can increase up to 35 at only 20 vol. \% [8]. Therefore, low-loss magnetic liquid silicone rubber composite material with a high permeability was used to fabricate the primary and the secondary pot cores. These soft magnetic encapsulations shape and guide the magnetic flux at a low magnetic resistance and consequently enhance the power transfer efficiency of the WPT module. In the design process, the geometries of the pot cores were optimized to maximize the power transfer efficiency.

Finally, to ensure a compatibility with various cardiac assist devices, the module was designed according to the international Qi-standard, widely applied by manufacturers of WPT systems. Although this standard is mostly used for technical applications such as cellphone or laptop charging [9], it could also be adopted as an international standard for WPT modules in medical applications. This may guarantee the interoperability of implants from different companies. It will also allow for drawing economies of scale with the electronic components needed e.g. specific controller chips.

In related work, presented in [6], the two-port network approach is employed to achieve the maximum possible power efficiency for a WPT system by defining an optimum load. However, the safety consideration and biocompatibility of the implants are not examined. [10] introduces resonance-based wireless power delivery with four coils applicable for implantable devices. [11] proposes a design method for magnetic resonant wireless power transfer with four-coil system applicable in bio-implantable devices to maximize the efficiency. However, systems with four coils have the disadvantages of a high-cost implementation, large size and an increased system complexity. Moreover, the effect of organic tissues on the efficiency is not investigated in [10] and [11], also the safety consideration and biocompatibility of the WPT modules are not studied. In [12], the optimal frequency, suitable for small-sized WPT in contact with a dispersive medium, is investigated. The authors conclude, that the optimal frequency to fit the trade-off between received and absorbed power by the dispersive tissue is in the $\mathrm{GHz}$ range. However, at this frequency range, the power absorption in human tissue is significant, eliminating this frequency range for medical applications requiring high power transfer for operation. A highly efficient WPT system, applicable to implants, using resonant load transformation is proposed in [13]. However, the safety consideration and the WPT system's biocompatibility is not examined. [14] introduces a multicoil-based WPT system for retinal implants. The design ensures a stable efficiency in the case of a coil misalignment. Moreover, a clear implantation scenario is introduced. However, the safety condition and the biocompatibility of the WPT module is not investigated. In [15], the design of an inductive wireless power transfer to operate an implantable semi-active UHF RFID tag is targeted. [16] proposes an impedance matching optimization technique to enhance the efficiency. A design of a WPT system for an implantable glaucoma therapeutic prototype is reported. In [15] and [16], the safety condition is not checked. In [17], a design for a highly efficient, integrated WPT system in a biomedical implant is introduced. Moreover, the specific absorption ratio as a safety measure is simulated. The critical mentioned points for a four-coil system are also valid for this work. To avoid the battery for an implanted medical device, in [18], an optimized large size WPT is employed. The enhanced WPT is obtained by optimizing the configuration of the coils. However, due to its large geometry, it cannot be applied for heart assist devices.

The focus of previous works in this field is on enhancing the WPT efficiency. However, in most cases, a clear implantation scenario or a specific application for WPT modules is not reported. Moreover, the optimization of WPT modules with biological tissue present and under the biological boundary conditions is not carried out. Finally, the thermal behavior of modules, regarding the design's geometry, thermal properties of the employed materials and currents flow through the coils, are not precisely verified.

For use in this contribution a distinction between the terms WPT module and WPT system is important. WPT module refers to the primary and secondary coils and their corresponding cores used to transfer the power, while WPT system describes the complete framework of the WPT module together with necessary circuitry. Moreover, primary side refers to the extracorporal primary coil together with the primary core, and secondary side refers to the implanted secondary coil together with the secondary core.

This paper is organized as follows. In Section II, the design considerations and challenges for a typical implantable WPT module are discussed. Section III introduces three WPT modules. Section IV suggests a methodology to evaluate the performance of each module. In Section V, the field, circuit and thermal simulation results of the three WPT modules are discussed and their performances are compared. Section VI concludes this contribution. Finally, the exact core material characterization technique is shown in appendix I.

\section{Design Considerations}

\section{A. Integration Concept}

To integrate a WPT module in a VAD, the drive line cable has to be replaced by two elements, the primary side outside the body (i.e. employed as the power transmitter and placed 


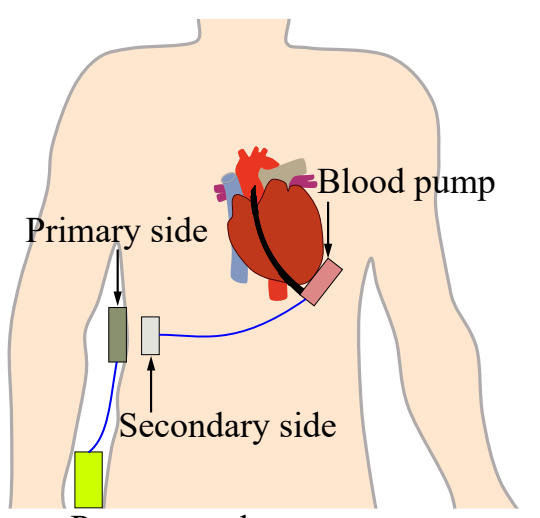

Power supply

Fig. 1: Concept of the WPT module integration in cardiac assist devices. The primary side is located on the skin surface (extracorporal), while the secondary side is implanted under the skin (intracorporal) parallel to the primary side.

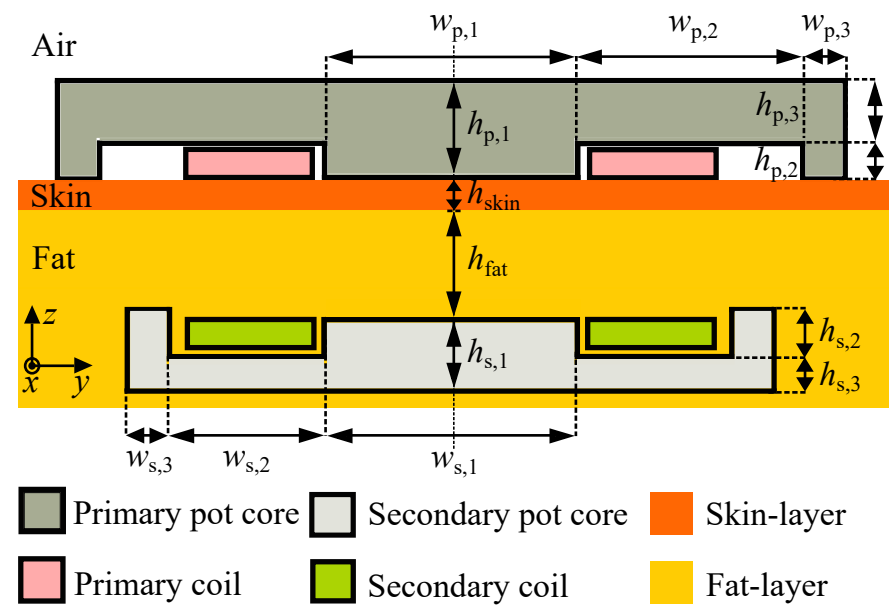

Fig. 2: Geometry of the primary and secondary sides. The primary core together with the primary coil are placed on the skin surface, while the secondary core together with the secondary coil are implanted under the skin surface in the fat-layer.

directly on the skin) and the secondary side inside the body (i.e. used as the power receiver and embedded under the skin). The concept of the WPT module integration in the VAD is shown in Fig. 1. The power supply includes two batteries and the control unit which serve as energy source and power level management, respectively.

A detailed description of the geometry of the setup is shown in Fig. 2. Since the biocompatibility of the coil material is not verified in this work, for the practical realization, the secondary coil can be coated by a confined silicon rubberlayer to avoid physical contact with the fat-layer.

To enhance power transfer efficiency, it is necessary to find optimal values for the mechanical dimensions shown in Fig. 2, with some constrains regarding human anatomy.

Since the size of the module, especially the secondary side, is also a critical design consideration [4], it was designed in a more compact form.
TABLE I: ELECTROMAGNetic AND THERMAL PROPERTIES OF SKIN AND FAT AT $110 \mathrm{kHz}$.

\begin{tabular}{lccc}
\hline Parameters & Skin & Fat & Units \\
\hline Relative permittivity & 1120 & 96.2 & - \\
Relative permeability & 1 & 1 & - \\
Density & 1109 & 911 & $\mathrm{kgm}^{-3}$ \\
Electrical conductivity & 0.000498 & 0.0434 & $\mathrm{~S} \mathrm{~m}^{-1}$ \\
Heat capacity & 3391 & 2348 & $\mathrm{~J} \mathrm{~kg}^{-1}{ }^{\circ} \mathrm{C}^{-1}$ \\
Thermal conductivity & 0.37 & 0.21 & $\mathrm{~W} \mathrm{~m}^{-1}{ }^{\circ} \mathrm{C}^{-1}$ \\
$\begin{array}{l}\text { Average emissivity } \\
\text { of the human body }\end{array}$ & 0.97 & - & - \\
Convective heat transfer & 3 & - & $\mathrm{Wm}^{-2}{ }^{\circ} \mathrm{C}^{-1}$ \\
coeff. in the chest region & & & \\
Blood flow & 9000 & 2000 & $\mathrm{Wm}^{-3}{ }^{\circ} \mathrm{C}^{-1}$ \\
Metabolic rate & 2000 & 300 & $\mathrm{Wm}^{-3}$ \\
\hline
\end{tabular}

\section{B. Physical and Thermal Environment Properties}

Owing to the lower absorption at very low frequencies $(100 \mathrm{kHz}$ to $4 \mathrm{MHz})$, the tissue loss is significantly decreased in this frequency range [10], [19]. Therefore, these frequencies are suitable for the operation in the case of using transcutaneous power transfer modules. The proposed WPT module is optimized for a nominal operational frequency of $110 \mathrm{kHz}$.

Relevant tissues for simulation are the skin- and the fatlayers. The material properties of skin and fat at the nominal frequency of $110 \mathrm{kHz}$ are summarized in Table I [20]-[24].

The body temperature is typically $37^{\circ} \mathrm{C}$ and the temperature of the skin surface, which corresponds to an implantation location in the chest, in stable thermal environments is on average bellow $37^{\circ} \mathrm{C}$ [25]. Moreover, the room temperature exhibits a range value as between $20^{\circ} \mathrm{C}$ to $25^{\circ} \mathrm{C}$ [26].

However, to consider the worst case scenario, in the simulation process, the temperature of the skin and the area around the primary core outside the human body was chosen as $37^{\circ} \mathrm{C}$.

\section{Safety: EM Exposure to Human Body}

Since the proposed WPT module needs to be implanted in the human body, its compliance with safety regulations has to be verified. The penetration of the electromagnetic fields into the body causes heat and thus an increase of the body temperature. A certain level of heat can be tolerated by the body, however, above this threshold, the electromagnetic exposure causes tissue injuries, such as burns. To avoid this hazard, the International Commission on Non-Ionizing Radiation Protection (ICNIRP) organization approves exposure limits (basic restrictions) to static and time-varying electric and magnetic fields for a high level of protection at various frequencies [27].

To keep the body at a safe level, the rise of body core temperature, due to the electromagnetic fields radiation in the range of $100 \mathrm{kHz}$ to $6 \mathrm{GHz}$, should not exceed $+1^{\circ} \mathrm{C}$. For localized heating, however, biological tissue damage occurs at temperatures above $41^{\circ} \mathrm{C}$. Therefore, for the Head and Torso region, containing the head, eyes, abdomen, back, thorax and pelvis with the typical temperature being $38^{\circ} \mathrm{C}$ to $38.5^{\circ} \mathrm{C}$, the rise in local temperature is not allowed to exceed $2{ }^{\circ} \mathrm{C}$; for the Limb region, comprising the upper arms, forearms, 


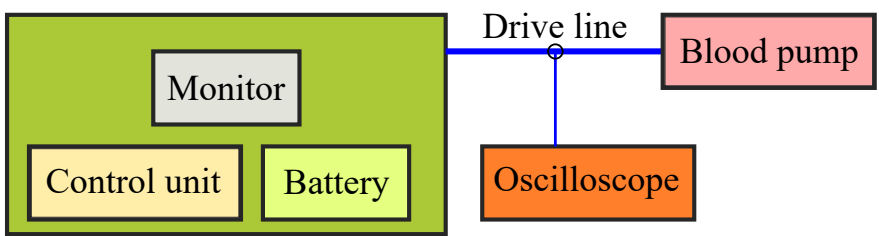

Fig. 3: Schematic of the HeartWare HVAD system. VAD components: Touch screen monitor, control unit, two batteries, driveline cable and blood pump. Oscilloscope was connected to the drive line cable with removing its insulation.

hands, thigh, legs and feet with a typical temperature of $33^{\circ} \mathrm{C}$ to $36^{\circ} \mathrm{C}$, the local temperature increase must be kept within $+5{ }^{\circ} \mathrm{C}[28]$.

Moreover, from [6] we can conclude that the temperature increase in small biological tissues should not exceed $1{ }^{\circ} \mathrm{C}$. For this reason and also regarding to the defined body and environment temperature in II-B, the maximum allowed temperature was considered as $38^{\circ} \mathrm{C}$.

\section{Power Requirements for VAD Operation}

VADs are electromechanical pump systems used to support failing ventricles in vital task, and therefore, to assist the deficient heart by taking over its function partially or entirely. The blood pump is implanted in parallel to the heart and facilitates the blood circulation by accelerating the blood flow.

Due to the varying daily activities of the patient, the blood flow rate has to be adapted to the changing load conditions. This is achieved by increasing or decreasing the input power of the blood pump [1]-[4], [29]-[33].

In order to provide a realistic setup, the focus in this contribution lies on the Heartware HVAD system (HeartWare Inc. [34]). The schematic of the HVAD is shown in Fig. 3. In [35], the relationship between the VAD input power, required to operate the rotary motor inside the blood pump, and the rotational speed of the rotary motor is shown. The rotational speed and the input power depend on several parameters such as the gender, weight, age, heart failure stage and current physical activity of the patient [36]. For clinical treatments, the rotational speed (in revolutions per minute: $[\mathrm{RPM}]$ ) mostly remains between $2400 \mathrm{RPM}$ and 2800 RPM [35]. In the region of normal operation, the power consumption lies between $2.7 \mathrm{~W}$ and $4.6 \mathrm{~W}$. For the design of the system, $4.6 \mathrm{~W}$ was considered as the maximum average required power and thus the worst case scenario.

Whereas the above mentioned parameters can be obtained from [35], further parameters had to be assessed experimentally. For that purpose, a training Heartware system was employed (see Fig. 3). After having removed the outer insulation of the drive line, $\mathrm{AC}$ voltages and currents for the minimal average (2400 RPM, $2.7 \mathrm{~W}$ ) and maximal average (2800 RPM, $4.6 \mathrm{~W})$ configurations were measured as $(1.73 \mathrm{~V}, 1.55 \mathrm{~A})$ and $(2.24 \mathrm{~V}, 2 \mathrm{~A})$, respectively. This measurement was repeated for several rotational speeds from $2400 \mathrm{RPM}$ to $2800 \mathrm{RPM}$ and their corresponding average power levels, as well as for $2.2 \mathrm{~W}$ and $5.6 \mathrm{~W}$ at $2400 \mathrm{RPM}$ and
2800 RPM, respectively. It was concluded that the voltagecurrent ratio of the measurements remains unchanged and hence the rotary motor can be considered as a resistance load with a value of $1.12 \Omega \pm 0.1 \Omega$.

\section{E. Compatibility of the WPT Module with the Qi-Standard}

Two planar coils were used in the design process as the primary and secondary coils, with a nominal distance of $10 \mathrm{~mm}$ [6], [16]. The WPT system was then optimized to inductively transfer $4.6 \mathrm{~W}$.

The international Qi-standard, developed for WPT applications, ensures the interoperability between the products of various manufactures. The relevant practical features, defined for low power devices, also suited for wearable applications, are summarized as [9], [37], [38]:

1) Wireless power delivery among planar coils based on magnetic induction

2) Power transfer range of up to $15 \mathrm{~W}$

3) Operational frequency band of typically [87-205]-kHz

4) Distance transmission range between $5 \mathrm{~mm}$ to $40 \mathrm{~mm}$.

The WPT module design considerations comply with the Qi-standard.

\section{Design of the CoIl CORES}

\section{A. WPT Module 1: Coils without Cores}

To achieve high efficiency and thermal compatibility, [39] proposes the use of low-loss coils in WPT modules, made of litz wires, to manage skin and proximity effects and thus keep AC resistance low.

For the proposed WPT module, two identical planar wireless power charging transmitter coils (Würth Elektronik [40]), made of litz wires, with the maximum Q-factor in the range of $100-200 \mathrm{kHz}$ were employed as the primary and secondary coils as shown in Fig. 4a. Since the coil is light and compact, Qi-standard compatible, applicable for more than $15 \mathrm{~W}$ and exhibits a low AC resistance, it is an excellent candidate for the WPT module.

\section{B. WPT Module 2: Coils with Pot Cores}

1) Dimensions Optimization: The fraction of the entire magnetic flux emanating from the primary side and flowing through the secondary side can be described by the coupling coefficient. The objective was to optimize the dimensions of the pot cores $w_{\mathrm{p} / \mathrm{s}, \mathrm{i}}$ and $h_{\mathrm{p} / \mathrm{s}, \mathrm{i}}(\mathrm{i}=1,2$ and 3), shown in Fig. 2, so that the coupling coefficient, defined as

$$
k=\frac{M}{\sqrt{L_{\mathrm{p}} L_{\mathrm{s}}}},
$$

is maximized [41]. In (1), $L_{\mathrm{p}}$ and $L_{\mathrm{s}}$ are the inductances of the primary side and secondary side, respectively, and $M$ describes the mutual inductance. To this end, the optimization of this WPT module was carried out with a computer-aided design process, i.e., with CST EM Studio software (Low Frequency Domain Solver). 


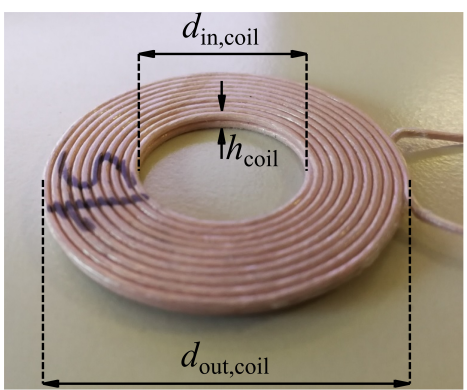

(a)

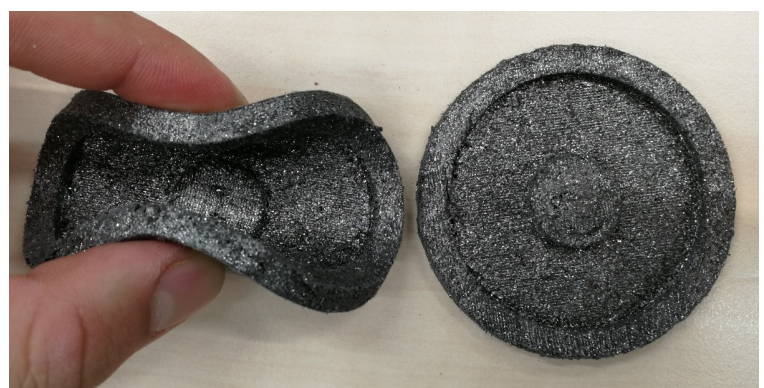

(b)

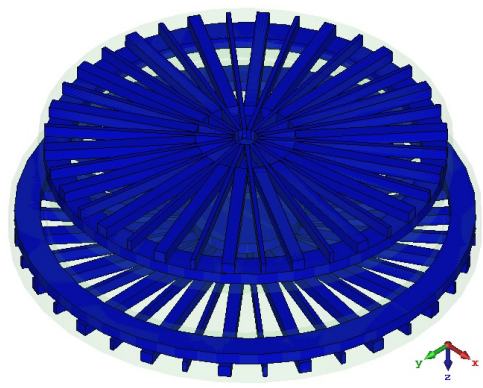

(c)

Fig. 4: (a) Double-layer coil with 20 windings used in the proposed WPT modules: $d_{\text {in,coil }}=20.5 \mathrm{~mm}, d_{\text {out,coil }}=42.9 \mathrm{~mm}$ and $h_{\text {coil }}=2.3 \mathrm{~mm}$ (used in WPT modules 1, 2 and 3).

(b) Fabricated primary and secondary pot cores (designed and used in WPT modules 2 and 3).

(c) Flexible ferromagnetic inserts embedded in the primary and secondary pot cores, to further enlarge the WPT system efficiency (designed and used in WPT module 3).

The relative permittivity, relative permeability and electrical conductivity of the core material were measured at the LSP Institute of Polymer Materials at the Friedrich-AlexanderUniversity Erlangen-Nuremberg, and obtained as $2.8,12$ and $5 \times 10^{-13} \mathrm{Sm}^{-1}$, respectively. These values were applied as the first estimation of the core material characteristics in the simulation process. Moreover, in the simulation, the secondary side was placed in the fat-layer $\left(h_{\text {fat }}=8.05 \mathrm{~mm}\right.$ ) [42], under a $1.95 \mathrm{~mm}$ thick skin-layer $\left(h_{\text {skin }}=1.95 \mathrm{~mm}\right)$ [43].

2) Fabrication Process: The filler powder was obtained by grinding the nanocrystalline soft magnetic material Vitroperm 250 (VACUUMSCHMELZE GmbH \& Co. KG.) to a coarse and fine primary powder by a variable speed rotor mill PULVERISETTE 14 (FRITSCH GmbH). The primary powders were sieved with a test sieve shaker according to DIN 66 165-1 with sieves of a mesh width 500, 250, 150, 100 and $63 \mu \mathrm{m}$ [44]. The detailed powder production process is explained in [8]. The fraction between the sieves 150 and $100 \mu \mathrm{m}$ was chosen to ensure sufficient permeability and good molding accuracy. As silicone matrix two component high temperature vulcanizing liquid silicone rubber Elastosil LR 3003/3 (Wacker Chemie AG) was weight out at a ratio of 1:1, mixed in a speed mixer and degassed by a desiccator. The fraction between the sieves 100 and $63 \mu \mathrm{m}$ was weight out at $40 \mathrm{vol} . \%$ and mixed with the liquid silicone rubber in a speed mixer. The compound was poured in a $3 \mathrm{D}$ printed ABS mold resembling a negative of the pot cores. The compound was again degassed in a desiccator and crosslinked at $90^{\circ} \mathrm{C}$ for 16 hours.

The pot cores were characterized at the LSP Institute of Polymer Materials at FAU and are shown in Fig. 4b. The measured permeability of the core material due to its inhomogeneity is not accurate and includes a deviation of $12 \pm 4$. As the exact value is of importance, the core material was accurately characterized according to the procedure described in appendix A.

Moreover, the alternating magnetic loss tangent $\left(\tan \delta_{m}\right)$ of the core material was measured as less than 0.01 [7]. Therefore, the imaginary part of the permeability was assumed
TABLE II: Electromagnetic AND Thermal Properties OF THE CORE MATERIAL.

\begin{tabular}{lcc}
\hline Parameters & Pot cores & Units \\
\hline Relative permittivity & 2.8 & - \\
Relative permeability & 9.5 & - \\
Density & 1010 & $\mathrm{kgm}^{-3}$ \\
Electrical conductivity & $5 \times 10^{-13}$ & $\mathrm{Sm}^{-1}$ \\
Heat capacity & 1250 & $\mathrm{Jkg}^{-1}{ }^{\circ} \mathrm{C}^{-1}$ \\
Thermal conductivity & 1 & $\mathrm{Wm}^{-1}{ }^{\circ} \mathrm{C}^{-1}$ \\
Emissivity & 0.9 & $-\mathrm{Wm}^{-2}{ }^{\circ} \mathrm{C}^{-1}$ \\
Convective heat transfer coeff. & 5 & $\mathrm{Wm}^{-}$
\end{tabular}

to be neglectable and was set to 0 in the simulation.

The results as well as further physical properties of the pot cores, which were also measured at the operational frequency, are summarized in Table II.

3) Biocompatibility Test of the Core Material: Biocompatibility denotes the ability of biomaterials to be deployed in medical therapies without provoking adverse effects for biological tissues [45]. To verify the biocompatibility of the core material the following experiment was performed at the Department of Cardiac Surgery at the University Hospital Erlangen:

As a first step to assess biocompatibility, in-vitro cytotoxity was investigated as proposed in ISO 10993-5:2009 [46]. Human Saphenous Vein Endothelial Cells (HSVEC) were cultivated for 14 days in direct contact with the different core material samples and cell proliferation was assessed qualitatively and quantitatively.

PrestoBlue ${ }^{\circledR}$ Cell Viability Reagent A 13261 (from Invitrogen, Thermo Fisher Scientific Inc.) was added to the cell cultures on day $1,4,6,8,11$ and 13 and the resulting colour changes were measured via absorption.

\section{WPT Module 3: Coils with Cores Containing Ferromagnetic Inserts}

To further increase the coupling coefficient and consequently the efficiency, a new design, shown in Fig. 4c, is 
TABLE III: Electromagnetic And Thermal ProperTIES OF THE INSERTS.

\begin{tabular}{lcc}
\hline Parameters & Inserts & Units \\
\hline Relative permittivity & 6.9 & - \\
Relative permeability & 230 & - \\
Density & 4750 & $\mathrm{kgm}^{-3}$ \\
Electrical conductivity & $5 \times 10^{-5}$ & $\mathrm{Sm}^{-1}$ \\
Heat capacity & 750 & $\mathrm{Jkg}^{-1}{ }^{\circ} \mathrm{C}^{-1}$ \\
Thermal conductivity & 4 & $\mathrm{Wm}^{-1}{ }^{\circ} \mathrm{C}^{-1}$ \\
\hline
\end{tabular}

proposed. The low-loss, high permeability $(\approx 230)$ flexible ferrite sheets are formed out of the blue inserts and then embedded in the magnetic primary and secondary pot cores during the fabrication process [47]. The material properties of the inserts were measured at the operational frequency and the results are summarized in Table III.

The optimization of the geometry of the inserts was also carried out in CST software.

\section{Performance Evaluation: Methodology}

\section{A. Module Characterization}

To evaluate the performance of the WPT modules 1,2 and 3 , they were individually simulated in the CST software. The simulation enabled us to determine the electrical characteristics of the modules such as the primary side-, secondary side- and also the mutual inductances. To verify the obtained inductances in the simulations for the WPT modules 1 and 2, two measurements were performed in air with an impedance/gain-phase analyzer (4194A HP Inc.).

To determine the primary side inductance, the primary coil was connected to the impedance analyzer, while the secondary coil was left open. The same procedure was performed to measure the secondary side inductance. To measure the mutual inductance, the primary coil was connected in series with the secondary coil, the two remaining free cables of the primary and secondary coils were connected to the impedance analyzer.

Moreover, to verify the behavior of the magnetic flux density (B $[\mathrm{T}])$ versus the magnetic field intensity $\left(\mathrm{H}\left[\mathrm{Am}^{-1}\right]\right)$, a ring core fabricated with the same material used in the pot cores was characterized at the Chair of Electron Devices at FAU [48]. The ring core before and after winding is shown in Fig. 5.

\section{B. WPT System Design: WPT Module and Circuitry}

The application of an AC voltage in a WPT module generates both active and reactive power. The system consumes the active power, while the undesired reactive power circulates in the WPT components, oscillating between the magnetic and electrical circuits [49]. However, the reactive power can be compensated by decreasing the equivalent reactance at both power transmitter and receiver circuits [50]. This can be achieved by employing two resonant networks at the primary and secondary sides, consisting of two capacitors $C_{\mathrm{p}}$ and $C_{\mathrm{s}}$ in series with the primary side with the inductance of $L_{\mathrm{p}}$ and the secondary side with the inductance of $L_{\mathrm{s}}$, respectively. This

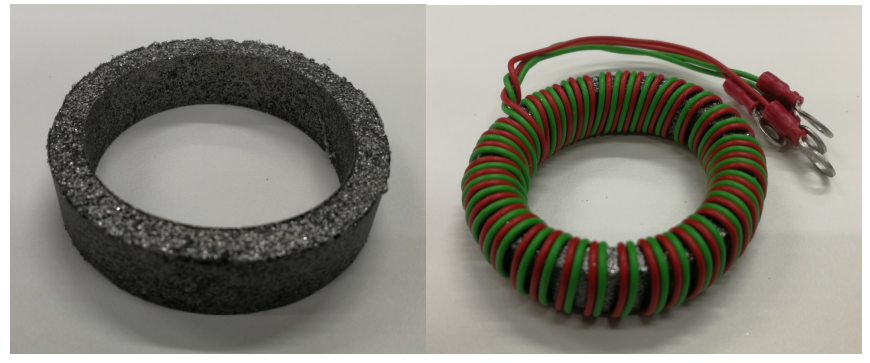

(a)

(b)

Fig. 5: Ring core before and after winding. (a) Inner diameter $=40.5 \mathrm{~mm}$, thickness $=5.1 \mathrm{~mm}$ and hight $=10.7 \mathrm{~mm}$. (b) 40 turns primary winding and 40 turns secondary winding.

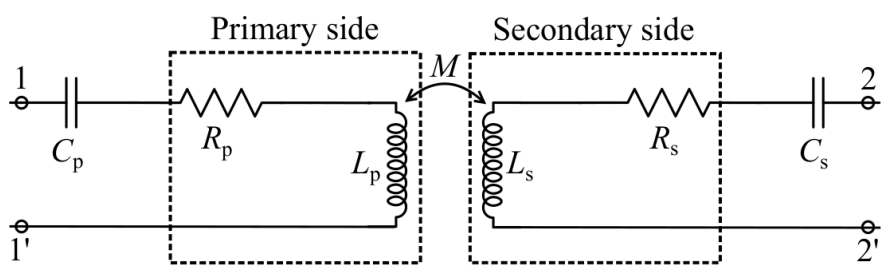

Fig. 6: Equivalent circuit for the primary and secondary sides with the compensation capacitors.

ensures the highest voltage gain across the loadless-primary and -secondary sides [51]. The capacitors $C_{\mathrm{p}}$ and $C_{\mathrm{s}}$, given by [52]

$$
C_{\mathrm{p} / \mathrm{s}}=\frac{1}{\omega_{0}^{2} L_{\mathrm{p} / \mathrm{s}}} \text { where } \omega_{0}=2 \pi f_{0},
$$

were connected to the primary and secondary sides, respectively, as shown in Fig. 6.

To reduce the signal reflection at port 2 and ensure the maximum power transfer efficiency, the conjugate image impedance technique was applied for the secondary side. To this end, a resistance $\left(Z_{\mathrm{s}}\right)$, given by [53]

$$
Z_{\mathrm{s}}=R_{\mathrm{s}} \sqrt{1+\frac{\left(\omega_{0} M\right)^{2}}{R_{\mathrm{p}} R_{\mathrm{s}}}},
$$

was assumed to be connected to port 2 at the secondary side.

For the power transferred to the pump $P_{\mathrm{L}}$, the corresponding input voltage can be calculated as [54]

$$
V_{11^{\prime}}=\sqrt{\frac{P_{\mathrm{L}}\left[\left(\omega_{0} M\right)^{2}+R_{\mathrm{p}}\left(Z_{\mathrm{s}}+R_{\mathrm{s}}\right)\right]^{2}}{\left(\omega_{0} M\right)^{2} Z_{\mathrm{s}}}} .
$$

Finally, the power transfer efficiency of the WPT system is given by

$$
\eta=\frac{P_{\mathrm{L}}}{P_{11}}
$$

where $P_{11}$ is the generated power from the voltage source. The exact value of the efficiency can only be calculated, if the power loss due to the human tissues surrounding the coils is taken into account. 
TABLE IV: OPtimized VALUES OF THE Dimensions OF THE PRimary AND SECONDARY Pot Cores (SEE Fig. 2). VAlues ARE GiVEn IN Millimeter.

\begin{tabular}{cccccc}
\hline$h_{\mathrm{p}, 1}$ & $h_{\mathrm{p}, 2}$ & $h_{\mathrm{p}, 3}$ & $w_{\mathrm{p}, 1}$ & $w_{\mathrm{p}, 2}$ & $w_{\mathrm{p}, 3}$ \\
5.5 & 2.4 & 3.1 & 19 & 22.5 & 5.9 \\
\hline$h_{\mathrm{s}, 1}$ & $h_{\mathrm{s}, 2}$ & $h_{\mathrm{s}, 3}$ & $w_{\mathrm{s}, 1}$ & $w_{\mathrm{s}, 2}$ & $w_{\mathrm{s}, 3}$ \\
5 & 3.2 & 2.2 & 19.4 & 17.6 & 5.9 \\
\hline
\end{tabular}

\section{Field and Thermal Simulation}

As mentioned in III-B.1, III-B.3 and IV-A, the optimization of the WPT modules 2 and 3 and also the performances comparison of the three WPT modules were carried out in the CST software. CST allows for a multiphysical simulation, namely EM-thermal coupling simulation. By applying the EM simulation, the inductances were obtained and consequently the optimizations became possible. Moreover, the losses were be calculated in the EM simulation. The losses were saved and imported into the coupled thermal solver (Thermal Steady State Solver). By defining the coils as heat sources and other required setting such as thermal surface properties and the bioheat properties of the relevant tissues and also considering the losses, the temperature distribution was obtained.

To correctly simulate losses and consequently the temperature, it was necessary to find the currents flowing through each coil of each WPT system.

\section{Simulation and Measurement Results}

\section{A. Module Characterization: Verification}

For the WPT module 1, the simulation results were obtained as $14.06 \mu \mathrm{H}$ for the primary coil, $14.10 \mu \mathrm{H}$ for the secondary coil and $4.38 \mu \mathrm{H}$ for the mutual inductance.

To verify the simulation results, the inductances and $\mathrm{AC}$ resistances of the primary coil and the secondary coil of the module 1 were measured at the operational frequency with the impedance analyzer. The measured values were $14.04 \mu \mathrm{H}, R_{\mathrm{p}}=0.061 \Omega$ for the primary coil and $14.02 \mu \mathrm{H}$, $R_{\mathrm{s}}=0.083 \Omega$ for the secondary coil. The mutual inductance was also measured as $4.37 \mu \mathrm{H}$. The simulation results hence perfectly coincided with the measured results.

In case of the WPT module 2, the optimal dimensions of the primary and secondary pot cores were obtained by optimizing the coupling coefficient. These dimensions are summarized in Table IV.

For WPT module 2, referring to the simulation results, the primary, secondary and the mutual inductances were obtained as $24.43 \mu \mathrm{H}, 23.48 \mu \mathrm{H}$ and $10.34 \mu \mathrm{H}$, respectively. To validate these results, the magnetic characteristics of WPT module 2 were measured with the impedance analyzer. The inductances of the primary and secondary sides were obtained as $L_{\mathrm{p}}=24.45 \mu \mathrm{H}$ and $L_{\mathrm{s}}=23.75 \mu \mathrm{H}$, respectively, and the mutual inductance as $M=10.35 \mu \mathrm{H}$. The simulation results again perfectly coincide with the measured results, also proving that the skin-layer and fat-layer bounded between the coils, at the chosen operational frequency, do not influence the WPT modules' magnetic characteristics. Moreover, it also shows

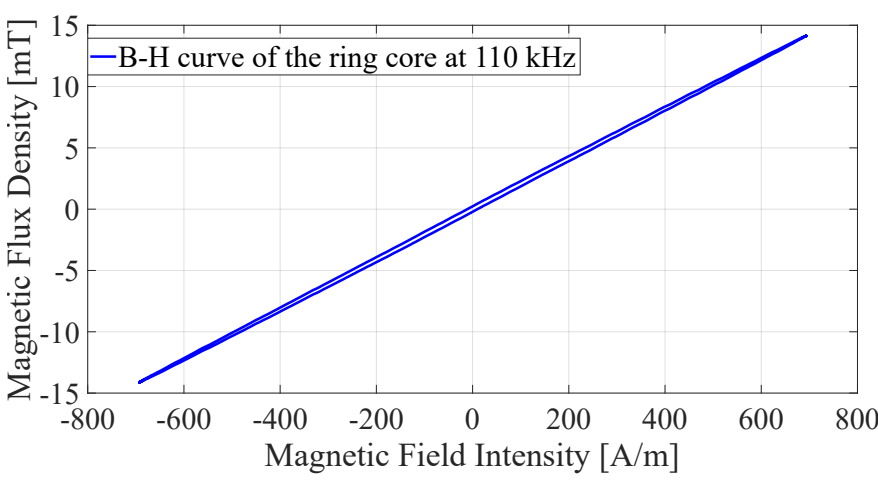

Fig. 7: Measured B-H hysteresis curve of the ring core (see Fig. 5) at $110 \mathrm{kHz}$ for magnetic field intensity $(\mathrm{H})$ between $-700 \mathrm{Am}^{-1}$ and $700 \mathrm{Am}^{-1}$.

that guiding the magnetic flux by the magnetic pot cores causes an increase in the values of the primary side, secondary side and mutual inductances and overall the coupling coefficient in comparison to WPT module 1.

For WPT module 3, the simulation results indicate that owing to the inserts embedded in the cores, the primary, secondary and mutual inductances were further increased to $32.42 \mu \mathrm{H}, 32.57 \mu \mathrm{H}$ and $16.94 \mu \mathrm{H}$, respectively.

Finally, the measured results for the ring core shown in Fig. 7, indicate that its B-H hysteresis curve perfectly shows a linear behavior for a wide range of the magnetic field intensity.

\section{B. Biocompatibility Test of the Core Material}

For the biocompatibility test of the core material, the following result was reported: HSVEC proliferated similar with all core material samples. A reduced cell count in all samples was observed compared to the control sample, which did not contain any material sample. This can be explained by the smaller available cultivation area due to the material sample in the culture well. The qualitative evaluation of the cells under the microscope showed no zone of reduced growth around the material samples and no changes in the cell morphology. Therefore, no reactivity with the material and no indication for cytoxity can be deduced. Of course, in order to confirm long-time biocompatibility further and broader tests have to be done with the selected core material.

\section{Circuit Simulation}

To carry out the field and thermal simulations for transferring $4.6 \mathrm{~W}$ to the pump, the currents flowing through the coils had to be obtained. For this purpose, the circuit shown in Fig. 6 was simulated in LTspice software (Linear Technology Corporation) for three WPT modules, in accordance with their corresponding electromagnetic characteristics, compensation capacitors and the optimal load at port 2 .

For instance, in case of WPT system 2 , the capacitors $C_{\mathrm{p}}$ and $C_{\mathrm{s}}$ were calculated as $85.61 \mathrm{nF}$ and $88.11 \mathrm{nF}$, respectively, and the optimal resistance $Z_{\mathrm{s}}$ as $8.34 \Omega$.

However, as mentioned in II-D, the resistance with a value of $1.12 \Omega$, representing the blood pump, was targeted as the load and therefore had to be connected to port 2. But this load 


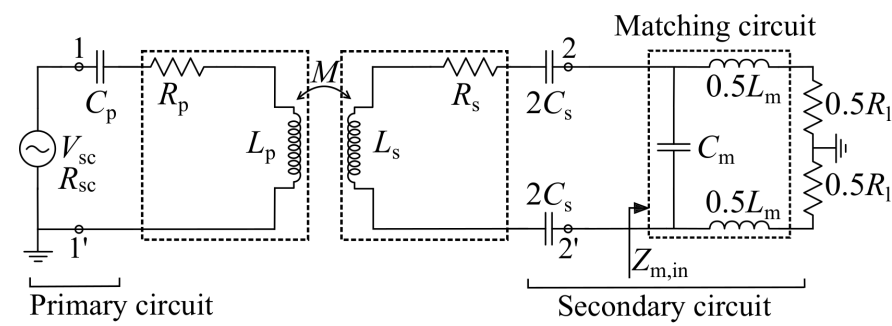

Fig. 8: Equivalent circuit of the WPT system optimized to meet the design requirements. $R_{\mathrm{L}}$ describes the electrical characteristic of the blood pump. For WPT module 2, the values are given as $L_{\mathrm{p}}=24.45 \mu \mathrm{H}, L_{\mathrm{s}}=23.75 \mu \mathrm{H}, M=10.35 \mu \mathrm{H}$, $R_{\mathrm{p}}=0.061 \Omega, R_{\mathrm{s}}=0.083 \Omega, C_{\mathrm{p}}=85.61 \mathrm{nF}, C_{\mathrm{s}}=88.11 \mathrm{nF}$, $Z_{\mathrm{m}, \mathrm{in}}=8.34 \Omega, C_{\mathrm{m}}=0.44 \mu \mathrm{F}, L_{\mathrm{m}}=4.11 \mu \mathrm{H}, R_{\mathrm{L}}=1.12 \Omega$ and $R_{\mathrm{sc}} \approx 0 \Omega$.

did not correspond to the optimum resistance $Z_{\mathrm{s}}$. To overcome the resistance mismatching, an impedance matching circuit with L-section was designed based on the input resistance $Z_{\mathrm{m}, \text { in }}=Z_{\mathrm{s}}=8.34 \Omega$ and the load resistance $R_{\mathrm{L}}=1.12 \Omega$ [55]. The resulting optimal design is shown in Fig. 8.

To realize a galvanic isolation and separate reference potentials on the primary side and secondary side, the secondary circuit was designed symmetric. As a result, the load resistance was split into two resistances with half the value of the load resistance.

To obtain the currents through the coils with each WPT system, three circuits, as shown in Fig. 8, were simulated with LTspice software. To transfer $4.6 \mathrm{~W}$ to the pump, in case of WPT system 1, $1740 \mathrm{~mA}$ flowed through the primary coil and $940 \mathrm{~mA}$ through the secondary coil, for WPT system 2, the currents of the primary and secondary coils were obtained as $874 \mathrm{~mA}$ and $732 \mathrm{~mA}$, respectively, and finally in case of the WPT system $3,681 \mathrm{~mA}$ and $572 \mathrm{~mA}$ flowed through the primary and secondary coils, respectively.

Owing to the low operational frequency, the average power loss in tissues for each WPT system was significantly lower (based on the simulation results: $4.15 \times 10^{-5} \mathrm{~W}$ for WPT system $1,3.32 \times 10^{-5} \mathrm{~W}$ for WPT system 2 and $3.73 \times 10^{-5} \mathrm{~W}$ for WPT system 3). Therefore, it can be disregarded when calculating overall efficiency. The coupling coefficient and efficiency of the WPT systems 1, 2 and 3 were obtained as $\left[k_{1}, \eta_{1}\right]=[0.31,83.42 \%],\left[k_{2}, \eta_{2}\right]=[0.43,95.22 \%]$ and $\left[k_{3}, \eta_{3}\right]=[0.52,96.33 \%]$.

\section{Field and Thermal Simulation: Evaluation}

To clarify the effect of power transfer efficiency on temperature, the field and thermal simulations were carried out for WPT modules 1,2 and 3 .

In order to compare the generated magnetic field intensities of the WPT modules 1, 2 and 3 under the same conditions in the simulation process, the current for both coils of the WPT modules was limited to $1 \mathrm{~A}$. The field simulation result for WPT module 1, shown in Fig. 9a, indicates that the magnetic field strength is moderately strong at front and back side of each coil. However, in case of WPT module 2, shown in Fig. 9b, owing to the high magnetic permeability of the two
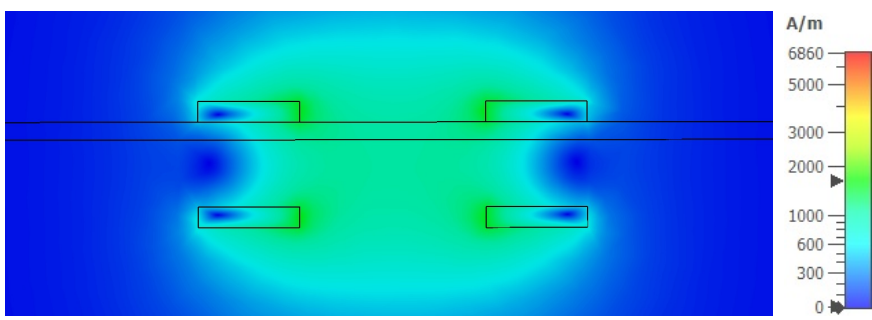

(a) WPT module 1
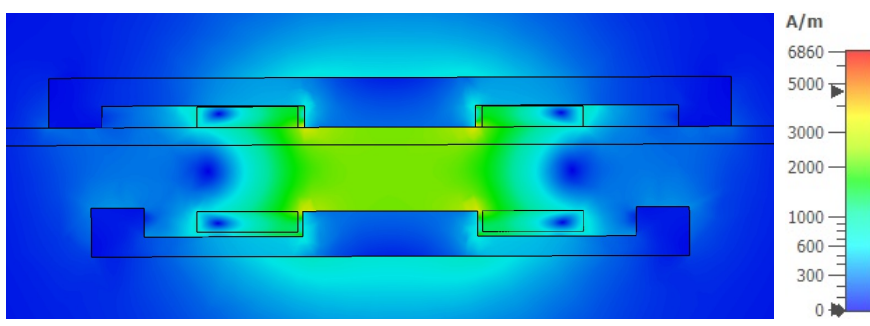

(b) WPT module 2
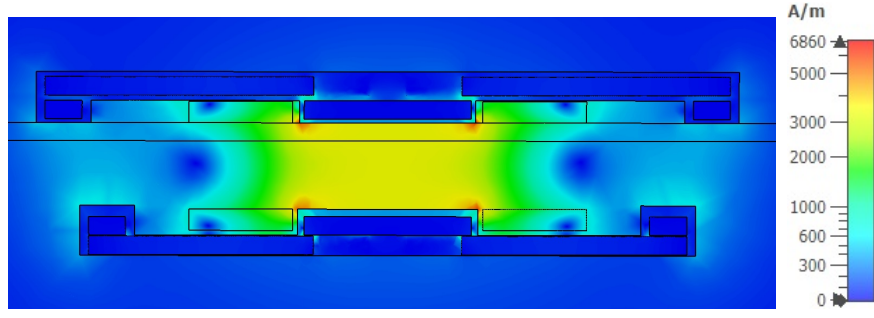

(c) WPT module 3

Fig. 9: Magnetic field intensity $\left(\mathrm{H}\left[\mathrm{Am}^{-1}\right]\right)$ distribution for the cross section of the WPT modules 1,2 and 3 through the symmetry axis (see also Fig. 2) for currents $I_{\mathrm{p}}=1 \mathrm{~A}$ and $I_{\mathrm{s}}=1 \mathrm{~A}$ flowing through the primary and secondary coil, respectively. By use of the pot cores in WPT module 2 and the ferromagnetic inserts in WPT module 3, maximum magnetic field intensity was increased from $1589 \mathrm{Am}^{-1}$ (WPT module 1) to $4322 \mathrm{Am}^{-1}$ (WPT module 2), and finally to $6860 \mathrm{Am}^{-1}$ (WPT module 3).

pot cores, the magnetic field strength is decreased at the back side of each coil, however, significantly increased between two coils. This is a consequence of the low magnetic resistance $R_{\mathrm{m}}$ of the pot cores, which guide the magnetic flux. It is guided in a way such that the magnetic flux mainly penetrates through both coils, which minimizes stray inductances and thereby increases mutual inductance and coupling coefficient. For the same reason, since the WPT module 3, thanks to the inserts with high permeability, exhibits the lower magnetic resistance, the magnetic field strength is consequently higher than for WPT module 2 .

For the thermal simulations the corresponding field simulations were carried out regarding to the obtained currents in section V-C.

For WPT module 1, to simulate the worst case scenario, the initial temperature of the skin-layer was set to $37^{\circ} \mathrm{C}$. According to the thermal simulation shown in Fig. 10a, the skin area in physical contact with the primary coil experiences a maximum temperature of $38.19^{\circ} \mathrm{C}$ after 3 hours. This 

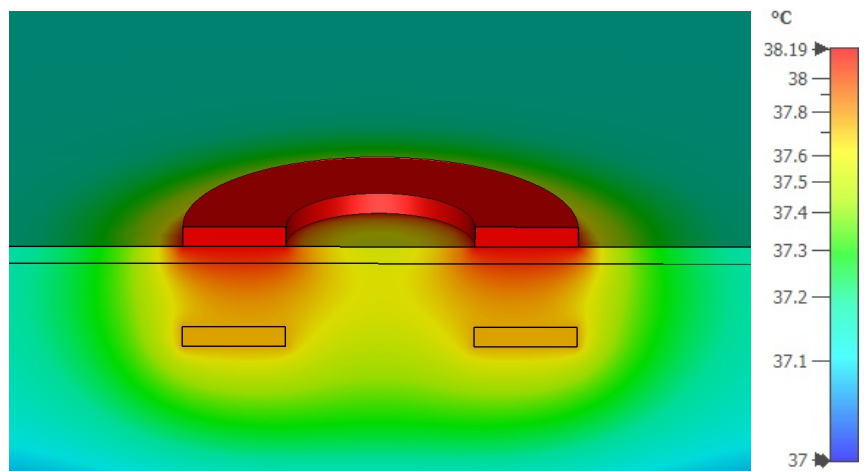

(a) WPT module $1: I_{\mathrm{p}}=1.74 \mathrm{~A}$ and $I_{\mathrm{s}}=940 \mathrm{~mA}$

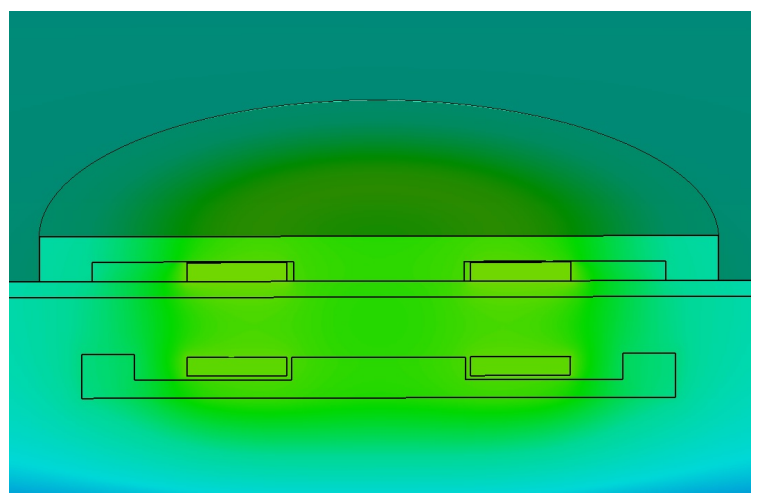

(b) WPT module 2: $I_{\mathrm{p}}=874 \mathrm{~mA}$ and $I_{\mathrm{s}}=732 \mathrm{~mA}$

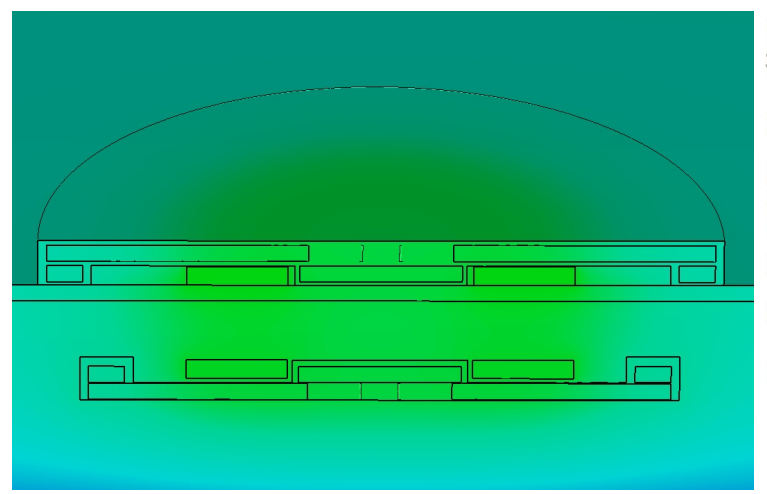

(c) WPT module 3: $I_{\mathrm{p}}=681 \mathrm{~mA}$ and $I_{\mathrm{s}}=572 \mathrm{~mA}$

Fig. 10: Temperature distribution after 3 hours for the cross section of the WPT modules 1, 2 and 3 through the symmetry axis (see also Fig. 2) for $4.6 \mathrm{~W}$ being wirelessly transferred to the pump. By use of the pot cores in WPT module 2 and the ferromagnetic inserts in WPT module 3 , the currents $I_{\mathrm{p}}$ and $I_{\mathrm{s}}$ flowing through primary and secondary coil were reduced while keeping the transferred power fixed. Consequently, maximum temperature decreased from $38.19^{\circ} \mathrm{C}$ (WPT module 1) to $37.38^{\circ} \mathrm{C}$ (WPT module 2), and finally to $37.27^{\circ} \mathrm{C}$ (WPT module 3$)$.

reflects an increase by $1.19^{\circ} \mathrm{C}$.

For WPT module 2, to simulate the worst case scenario, the initial temperatures of the skin-layer and the primary pot core were set to $37^{\circ} \mathrm{C}$. The corresponding thermal distribution is shown in Fig. 10b. The skin area in physical contact with the primary coil experiences a maximum temperature of about
TABLE V: COMPARISON OF WPT MOdULES 1, 2 AND 3.

\begin{tabular}{lcccc}
\hline \multirow{2}{*}{ Parameters } & \multicolumn{3}{c}{ WPT modules } & \\
& Module 1 & Module 2 & Module 3 & Units \\
\hline Transferred power & 4.6 & 4.6 & 4.6 & $\mathrm{~W}$ \\
Pri. side ind. & 14.04 & 24.45 & 32.42 & $\mu \mathrm{H}$ \\
Sec. side ind. & 14.02 & 23.75 & 32.57 & $\mu \mathrm{H}$ \\
Mutual ind. & 4.37 & 10.35 & 16.94 & $\mu \mathrm{H}$ \\
Coupling coeff. & 0.31 & 0.43 & 0.52 & - \\
Efficiency & 83.42 & 95.22 & 96.33 & $\%$ \\
Pri. coil current & 1.74 & 0.87 & 0.68 & $\mathrm{~A}$ \\
Sec. coil current & 0.94 & 0.73 & 0.57 & $\mathrm{~A}$ \\
Min. temp. & 37 & 37 & 37 & ${ }^{\circ} \mathrm{C}$ \\
Max. temp. & 38.19 & 37.38 & 37.27 & ${ }^{\circ} \mathrm{C}$ \\
\hline
\end{tabular}

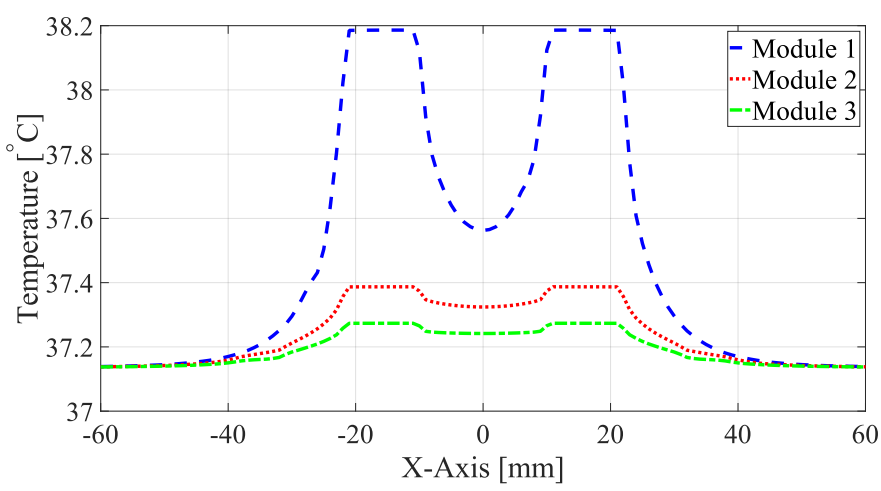

Fig. 11: 1D-temperature distribution on the $x$-axis $(y=0$ and $z=0$ ), where the primary coil touches the skin-layer. The application of pot cores decreases the maximum temperature and homogenizes the temperature distribution in the skin and fat.

$37.38^{\circ} \mathrm{C}$ after 3 hours reflecting an increase by $0.38^{\circ} \mathrm{C}$. This temperature remains in the safe level discussed in section II-C.

Finally, in case of WPT module 3 , by considering the worst case scenario, the maximum temperature was obtained as $37.27^{\circ} \mathrm{C}$ after 3 hours reflecting an increase by $0.27^{\circ} \mathrm{C}$, which truely is a very low increase.

\section{E. Summary of the System Performance}

The obtained critical parameters before and after optimization of the WPT modules are summarized in Table V.

Moreover, the temperature distribution for 3 WPT modules at the coordinates $y=0$ and $z=0$ on the $x$-axis are compared in Fig. 11. At this coordinate, the primary coil touches the skin-layer and the skin experiences the maximum temperature. Owing to the symmetry in the WPT design, the same results are obtained for all axes in the $x y$ plane at $z=0$. It is concluded that the application of pot cores not only decreases the maximum temperature, but it also homogenizes the temperature distribution in the biological-layers. Therefore, there is no risk of tissue burns.

\section{CONCLUSION}

Magnetic liquid silicone rubber composite cores applicable to WPT were designed, fabricated and validated. Owing to its biocompatibility and high magnetic conductivity, the core 
material is a perfect candidate to realize a high-efficiency WPT for medical applications. The measured results indicate that applying the cores in a typical WPT system, thanks to guiding magnetic flux, significantly increases the coupling coefficient, which guarantees a higher power transfer efficiency. This consequently ensures that for a certain amount of power transfer, lower currents are required. Therefore, the thermal compatibility for implants which need a significant amount of power for operation such as VADs, can be improved. In this contribution, the integration of WPT containing magnetic silicone cores in VADs was investigated. The integration scenario is to replace the part of the drive line, passing through the skin-layer, by the proposed implantable WPT to facilitate an inductive power transfer through the skin-layer, and as a result, to avoid a puncture of dermis. The results show an improved thermal compatibility when applying the cores. Moreover, by applying the pot cores in WPT, the temperature distribution is homogenized in the skin-layer and the fat-layer. Finally, its biocompatibility, flexibility and high magnetic conductivity make the proposed WPT design an excellent candidate for integration in cardiac assist devices such as VADs.

\section{ACKNOWLEDGMENT}

The authors gratefully acknowledge the support of Dr. rer. nat. Martina Ramsperger-Gleixner and Nina Koch for running the cytotoxicity experiments and Andreas Teske for his support with the training Heartware system.

The authors appreciatively thank Erik Friedel and Sara Kinner for their assistance in the optimization of the pot cores.

The authors sincerely acknowledge the support of Tobias Stolzke and Prof. Dr.-Ing. Martin März for the characterization of the ring core.

\section{APPENDIX I \\ Core Material Characterization}

As mentioned in section III-B.2, the first estimation for the permeability of the core material was $12 \pm 4$. Since the magnetic property of the core material is one of the crucial design parameters, it was necessary to characterize this material at the nominal operational frequency to guarantee a robust design. For this purpose, a set of simulations and measurements were carried out to find the exact permeability of the pot cores. First, the primary coil was simulated in CST with a current of $1 \mathrm{~A}$ flowing through the coil. The simulation results showed a relative deviation of $0.03 \mu \mathrm{H}$ from the measured result $\left(L_{\mathrm{p}_{-} \text {sim_1_coil }}=13.98 \mu \mathrm{H}\right.$ and $\left.L_{\text {p_meas_1_coil }}=13.95 \mu \mathrm{H}\right)$. Next, the primary and secondary coils with a separation distance of $10 \mathrm{~mm}$ were simulated. In both simulation and measurement procedures, one of the two coils was supplied with the current of $1 \mathrm{~A}$, while the other coil was left open. The simulation results coincided with the measured results $\left(L_{\mathrm{p} \_ \text {sim_2_coils }}=14.06 \mu \mathrm{H}\right.$ and $\quad L_{\text {p_meas_2_coils }}=14.04 \mu \mathrm{H}, \quad L_{\text {s_sim____coils }}=14.10 \mu \mathrm{H}$ and $L_{\text {s_meas_2_coils }}=14.02 \mu \mathrm{H}, M_{\text {sim_2_coils }}=4.38 \mu \mathrm{H}$ and $M_{\text {meas_2_coils }}=4.37 \mu \mathrm{H}$ ). Finally, the primary and secondary pot cores were added to the simulation. In the simulation, for the permeability of the cores with the value of 12 , the primary and secondary sides' inductances were obtained as $L_{\text {p_sim_2_coils_cores }}=25.68 \mu \mathrm{H}$ and $L_{\text {s_sim_2_coils_cores }}=24.75 \mu \mathrm{H}$ and the mutual inductance as $M_{\text {sim_2_coils_cores }}=11.25 \mu \mathrm{H}$. However, these results did not match the measured results mentioned in section III-B.2. To find the exact value of the permeability, in the simulation, the permeability of the core material was decreased in steps of 0.5 until the simulation results aligned with the measured results. A perfect matching was achieved for a permeability of 9.5, which resulted in $24.43 \mu \mathrm{H}$ for the primary side and $23.48 \mu \mathrm{H}$ for the secondary side and the mutual inductance of $10.34 \mu \mathrm{H}$. The slight deviation between the simulation and measured results are due to the measurement inaccuracy and the inhomogeneous core material characteristics, causing variable magnetic property.

\section{REFERENCES}

[1] Y. Yu, M. A. Simaan, S. E. Mushi and N. V. Zorn, "Performance Prediction of a Percutaneous Ventricular Assist System Using Nonlinear Circuit Analysis Techniques," in IEEE Transactions on Biomedical Engineering, vol. 55, no. 2, pp. 419-429, Feb. 2008.

[2] A. Verbeni et al., "An Innovative Adaptive Control Strategy for Sensorized Left Ventricular Assist Devices," in IEEE Transactions on Biomedical Circuits and Systems, vol. 8, no. 5, pp. 660-668, Oct. 2014.

[3] B. H. Waters, A. P. Sample, P. Bonde and J. R. Smith, "Powering a Ventricular Assist Device (VAD) With the Free-Range Resonant Electrical Energy Delivery (FREE-D) System," in Proceedings of the IEEE, vol. 100, no. 1, pp. 138-149, Jan. 2012.

[4] O. Knecht and J. W. Kolar, "Performance Evaluation of SeriesCompensated IPT Systems for Transcutaneous Energy Transfer,' in IEEE Transactions on Power Electronics, vol. 34, no. 1, pp. 438-451, Jan. 2019.

[5] B. Arkles, P. Redinger, "Silicones in Biomedical Applications" in Biocompatible Polymers, Metals and Composites, 1st ed. Lancaster PA, USA: Technomic Pub. Co, 1983, ch. 32, pp. 749-768.

[6] M. Zargham and P. G. Gulak, "Maximum Achievable Efficiency in Near-Field Coupled Power-Transfer Systems," in IEEE Transactions on Biomedical Circuits and Systems, vol. 6, no. 3, pp. 228-245, June 2012.

[7] D. W. Schubert, S. Werner, A. Heitbrink, "Magnetic Liquid Silicone Rubber - Revealing Effects and Process Limitations", in Macromolecular Symposia, vol. 372, issue. 1, pp. 140-146, April 2017.

[8] D. W. Schubert, S. Werner, I. Hahn, V. Solovieva, "Effect of particle size and size distribution on the permeability of soft magnetic liquid silicone rubber composites", in Composites Science and Technology, vol. 177, pp. 26-33, June 2019

[9] S. Y. Hui, "Planar Wireless Charging Technology for Portable Electronic Products and Qi," in Proceedings of the IEEE, vol. 101, no. 6, pp. 12901301, June 2013.

[10] A. K. RamRakhyani, S. Mirabbasi and M. Chiao, ”Design and Optimization of Resonance-Based Efficient Wireless Power Delivery Systems for Biomedical Implants," in IEEE Transactions on Biomedical Circuits and Systems, vol. 5, no. 1, pp. 48-63, Feb. 2011.

[11] X. Luo, S. Niu, S. L. Ho and W. N. Fu, "A Design Method of Magnetically Resonanting Wireless Power Delivery Systems for BioImplantable Devices," in IEEE Transactions on Magnetics, vol. 47, no. 10, pp. 3833-3836, Oct. 2011.

[12] A. S. Y. Poon, S. O'Driscoll and T. H. Meng, "Optimal Frequency for Wireless Power Transmission Into Dispersive Tissue," in IEEE Transactions on Antennas and Propagation, vol. 58, no. 5, pp. 17391750, May 2010.

[13] R. Xue, K. Cheng and M. Je, ”High-Efficiency Wireless Power Transfer for Biomedical Implants by Optimal Resonant Load Transformation,' in IEEE Transactions on Circuits and Systems I: Regular Papers, vol. 60, no. 4, pp. 867-874, April 2013.

[14] A. K. RamRakhyani and G. Lazzi, "Multicoil Telemetry System for Compensation of Coil Misalignment Effects in Implantable Systems," in IEEE Antennas and Wireless Propagation Letters, vol. 11, pp. 1675$1678,2012$.

[15] J. Kracek, M. Švanda, M. Mazanek and J. Machac, "Implantable SemiActive UHF RFID Tag With Inductive Wireless Power Transfer," in IEEE Antennas and Wireless Propagation Letters, vol. 15, pp. 16571660, 2016. 
[16] Z. Miao, D. Liu and C. Gong, "Efficiency Enhancement for an Inductive Wireless Power Transfer System by Optimizing the Impedance Matching Networks," in IEEE Transactions on Biomedical Circuits and Systems, vol. 11, no. 5, pp. 1160-1170, Oct. 2017.

[17] G. Sun, B. Muneer, Y. Li and Q. Zhu, "Ultracompact Implantable Design With Integrated Wireless Power Transfer and RF Transmission Capabilities," in IEEE Transactions on Biomedical Circuits and Systems, vol. 12, no. 2, pp. 281-291, April 2018.

[18] Y. Zeng, D. Qiu, X. Meng, B. Zhang and S. C. Tang, "Optimized Design of Coils for Wireless Power Transfer in Implanted Medical Devices," in IEEE Journal of Electromagnetics, $R F$ and Microwaves in Medicine and Biology, vol. 2, no. 4, pp. 277-285, Dec. 2018.

[19] D. Ahn and M. Ghovanloo, "Optimal Design of Wireless Power Transmission Links for Millimeter-Sized Biomedical Implants," in IEEE Transactions on Biomedical Circuits and Systems, vol. 10, no. 1, pp. 125-137, Feb. 2016

[20] P. Hasgall, F. Di Gennaro, C. Baumgartner, E. Neufeld, B. Lloyd, M. Gosselin, D. Payne, A. Klingenböck, N. Kuster, "IT'IS Database for Thermal and Electromagnetic Parameters of Biological Tissues," version 4.0, May 2018 [Online]. Available: https://itis.swiss/virtualpopulation/tissue-properties/database/database-summary/.

[21] R. Mohammadi-Baghaee and J. Rashed-Mohassel, "Broadband Explicit Time Domain Model for Human Skin Permittivity," in IEEE Transactions on Microwave Theory and Techniques, vol. 64, no. 8, pp. 26782683, Aug. 2016.

[22] R. J. de Dear, E. Arens, Z. Hui, M. Oguro, "Convective and Radiative Heat Transfer Coefficients for Individual Human Body Segments," in International Journal Biometeorology, vol. 40, no. 3, pp. 141-156, May 1997.

[23] Y. Kurazumi, T. Tsuchikawa, J. Ishii, K. Fukagawa, Y. Yamato, N. Matsubara, "Radiative and Convective Heat Transfer Coefficients of The Human Body in Natural Convection," in Building and Environment, vol. 43 , issue. 12 , pp. 2142-2153, Dec. 2008

[24] T. Togawa, "Non-Contact Skin Emissivity: Measurement from Reflectance Using Step Change in Ambient Radiation Temperature," in Clinical Physics and Physiological Measurement, vol. 10, no. 1, pp. 39-48, Feb. 1989.

[25] Y. Liu, L. Wang, J. Liu, Y. Di, "A Study of Human Skin and Surface Temperatures in Stable and Unstable Thermal Environments," in Journal of Thermal Biology, vol. 38, issue. 7, pp. 440-448, Oct. 2013.

[26] "Packaging and Storage Requirements 659," United States Pharmacopeia (USP), May 2017 [Online]. Available: https://www.uspnf.com/sites/default/files/usp_pdf/EN/USPNF/revisions/ 659_rb_notice.pdf.

[27] "International Commission on Non-Ionizing Radiation Protection," Registered in Munich, Germany, [Online]. Available: https://www.icnirp.org/en/frequencies/high-frequency/index.html.

[28] 'ICNIRP Guidelines for Limiting Exposure to Time-Varying Electric, Magnetic and Electromagnetic Fields (100 kHz to $300 \mathrm{GHz})$," ICNIRP RF Guidelines_PCD 201807 11, July 2018, [Online]. Available: https://www.icnirp.org/en/activities/public-consultation/consultation1.html

[29] Y. Wu, P. E. Allaire, G. Tao and D. Olsen, "Modeling, Estimation, and Control of Human Circulatory System With a Left Ventricular Assist Device," in IEEE Transactions on Control Systems Technology, vol. 15, no. 4, pp. 754-767, July 2007.

[30] B. Hentschel et al., "Interactive Blood Damage Analysis for Ventricular Assist Devices," in IEEE Transactions on Visualization and Computer Graphics, vol. 14, no. 6, pp. 1515-1522, Nov.-Dec. 2008.

[31] M. A. Simaan, A. Ferreira, S. Chen, J. F. Antaki and D. G. Galati, "A Dynamical State Space Representation and Performance Analysis of a Feedback-Controlled Rotary Left Ventricular Assist Device," in IEEE Transactions on Control Systems Technology, vol. 17, no. 1, pp. 15-28, Jan. 2009.

[32] G. Ochsner et al., "A Novel Interface for Hybrid Mock Circulations to Evaluate Ventricular Assist Devices," in IEEE Transactions on Biomedical Engineering, vol. 60, no. 2, pp. 507-516, Feb. 2013.

[33] A. Siewnicka and K. Janiszowski, "A Model for Estimating the Blood Flow of the POLVAD Pulsatile Ventricular Assist Device," in IEEE Transactions on Biomedical Engineering, vol. 65, no. 11, pp. 2552-2559, Nov. 2018.

[34] "HeartWare HVAD System," HeartWare. Inc, Part Nr. IFU00376 [Online]. Available: http://www.heartware.com.

[35] K. Chorpenning, M. C. Brown, N. Voskoboynikov, C. Reyes, A. E. Dierlam and D. Tamez, "HeartWare Controller Logs A Diagnostic Tool and Clinical Management Aid for the HVAD Pump," in ASAIO Journal, vol. 60, issue. 1, pp. 115-118, Jan-Feb. 2014.
[36] L. H. Lund, A. Gabrielsen, L. Tirén, A. Hallberg, K. El Kersten and M. J. Eriksson, "Derived and Displayed Power Consumption, Flow, and Pulsatility over a Range of HeartMate II Left Ventricular Assist Device Settings," in ASAIO Journal, vol. 58, issue. 3, pp. 183-190, May 2012

[37] G. Kiruthiga, M. Y. Jayant and A. Sharmila, "Wireless Charging for Low Power Applications Using Qi Standard," 2016 International Conference on Communication and Signal Processing (ICCSP), Melmaruvathur, 2016, pp. 1180-1184.

[38] "Qi System Description: Wireless Power Transfer," Wireless Power Consortium, vol. I: Low Power, part 1: Interface Definition, version 1.1, Apr. 2012 [Online]. Available: https://www.wirelesspowerconsortium.com/

[39] Y. Y. Ko, S. L. Ho, W. N. Fu and X. Zhang, "A Novel Hybrid Resonator for Wireless Power Delivery in Bio-Implantable Devices," in IEEE Transactions on Magnetics, vol. 48, no. 11, pp. 4518-4521, Nov. 2012.

[40] "WE-WPCC Wireless Power Charging Transmitter Coil," Order Nr. 760308100110 [Online]. Available: https://katalog.weonline.de/en/pbs/WE-WPCC-TRANSMITTER.

[41] R. Duarte, G. Klaric, "Analysis of the Coupling Coefficient in Inductive Energy Transfer Systems," in Active and Passive Electronic Components, vol. 2014, Article ID. 951624, June 2014.

[42] E. P. Doheny, B. M. Caulfield, C. M. Minogue and M. M. Lowery, "The effect of subcutaneous fat thickness on the efficacy of transcutaneous electrical stimulation," in 2008 30th Annual International Conference of the IEEE Engineering in Medicine and Biology Society, Vancouver, BC, 2008, pp. 5684-5687.

[43] A. Laurent, F. Mistretta, D. Bottigioli, K. Dahel, C. Goujon, J. F. Nicoals, A. Hennino, P. E. Laurent, "Echographic measurement of skin thickness in adults by high frequency ultrasound to assess the appropriate microneedle length for intradermal delivery of vaccines," in Vaccine, vol. 25, issue. 34, pp. 6423-6430, Aug. 2007.

[44] DIN Standards Committee Building and Civil Engineering. (2016). Particle Size Analysis - Sieving Analysis - Part 1: Fundamentals (DIN 66165-1).

[45] D. Williams, Biocompatibility and Performance of Medical Devices, 1st ed. Cambridge: Woodhead Publishing, 2012, ch. 1, pp. 3-17.

[46] International Organization for Standardization. (2009). Biological Evaluation of Medical Devices - Part 5: Tests for in Vitro Cytotoxity (ISO 10993-5:2009).

[47] "WE-FSFS Flexible Sintered Ferrite Sheet," Order Code 354003 [Online]. Available: https://www.weonline.de/katalog/datasheet/354003.pdf.

[48] T. Stolzke, S. Ehrlich, C. Joffe and M. März, "Comprehensive accuracy examination of electrical power loss measurements of inductive components for frequencies up to $1 \mathrm{MHz}$," in Journal of Magnetism and Magnetic Materials, vol. 497, issn. 0304-8853, March 2020.

[49] Handbook for Electricity Metering, 10th ed. Washington, D.C.: Edison Electric Institute, 2002, ch. 4, pp. 73-74.

[50] J. Dixon, L. Moran, J. Rodriguez and R. Domke, "Reactive Power Compensation Technologies: State-of-the-Art Review," in Proceedings of the IEEE, vol. 93, no. 12, pp. 2144-2164, Dec. 2005.

[51] U. Jow and M. Ghovanloo, "Design and Optimization of Printed Spiral Coils for Efficient Transcutaneous Inductive Power Transmission," in IEEE Transactions on Biomedical Circuits and Systems, vol. 1, no. 3, pp. 193-202, Sept. 2007.

[52] T. Campi, S. Cruciani, F. Maradei and M. Feliziani, "Near-Field Reduction in a Wireless Power Transfer System Using LCC Compensation," in IEEE Transactions on Electromagnetic Compatibility, vol. 59, no. 2, pp. 686-694, April 2017.

[53] N. Inagaki, "Theory of Image Impedance Matching for Inductively Coupled Power Transfer Systems," in IEEE Transactions on Microwave Theory and Techniques, vol. 62, no. 4, pp. 901-908, April 2014.

[54] W. Niu, J. Chu, W. Gu and A. Shen, "Exact Analysis of Frequency Splitting Phenomena of Contactless Power Transfer Systems," in IEEE Transactions on Circuits and Systems I: Regular Papers, vol. 60, no. 6, pp. 1670-1677, June 2013.

[55] J. I. Agbinya, Wireless Power Transfer, 2nd ed. Aalborg, Denmark: River Publishers, 2015, ch. 15 , pp. 523-529. 